M uch as I love sitting down with a paper copy of the EBM journal, the online version has functions that paper can never copy. Linkage to full text articles is one example. The abstracts give not only an excellent summary and commentary, but also l-click access to the full original text (if you want some more details), and to the references in the commentary. Similarly, Richard Lehman's "Evidently..." column provides links to the full text of the articles he discusses. The articles in Evidently are selected from the most relevant articles that don't quite make the list for full abstraction. As you can see, there are certainly some gems among these. For this issue, there were around 90 articles that were "b-listed" for possible inclusion in Evidently. And those came from the larger pool of several hundred articles from 100+ journals that passed our basic validity criteria (see the "Purpose and Procedure" for these criteria). But sadly, only around 5\% of current research articles pass these basic criteria. Of course, that's the advantage of reading the EBM journal: its 2 stage filter by quality then relevance means you only see the carefully selected gems from the world's major journals.

Do you have any comments or questions on the articles in EBM? We'd like to hear about your ideas, experience, questions, or problems on any of the articles. On the right hand bar in each article is a place for responses. So please click and tell!

\title{
EBM notebook
}

\section{Teaching evidence-based practice on foot}

\section{Come along to watch some clinical teachers in action:}

1. A hospital physician rounding with the team's medical students examines a middle aged woman with upper extremity deep vein thrombosis. After the bedside visit, the attending asks aloud about the frequency of underlying diseases associated with this condition, admits aloud he doesn't know the answer, and records the question concisely in his PDA.' After rounds, the attending invites the students along as he finds and appraises evidence about this topic and "thinks aloud" about how he'll use this knowledge in planning further testing.

2. An attending physician and 2 learners examine a patient with new onset congestive heart failure. After teaching how to hear a subtle S3 gallop with the stethoscope's bell, the physician explains the accuracy and precision of this finding as a test for heart failure and provides a reference for further learning. ${ }^{2}$

3. After starting emergent therapy for a patient's thyroid storm, an attending physician guides the team through the quantitative results of prognostic studies of this condition. The team then discusses how to use this evidence in counselling the patient. ${ }^{3}$

$\mathrm{T}$ hese teaching moments share 4 important features. Firstly, notice that the teaching is actually happening, despite the several barriers and disincentives clinical teachers face. ${ }^{4-5}$ Secondly, the teaching happens "on foot"that is, during the course of busy clinical work, rather than off site. ${ }^{6}$ Thirdly, while not exclusively so, these episodes involve teaching-in-context at the bedside. ${ }^{7-10}$ This essay examines a fourth shared feature, the use of evidence from clinical care research. In all 3 episodes, the attending made conscientious, explicit, and judicious use of either the process of evidence-based learning or its yield. ${ }^{11}$ The subtle but important variations in how this was done can be described as 3 different modes of teaching evidence-based practice, which are summarised in table $1 .{ }^{12-13}$

In the first encounter, the attending role-models evidencebased practice (mode 1 in table 1 ), combining the actual doing with the "think aloud" technique to guide the learners' attention to what is being done. By using mode 1, we show our learners how we incorporate evidence, along with other knowledge, into clinical decisions, so they come to see the use of evidence as part of good clinical practice. We show by our example that we really do it, and we can give pointers on when, where, and how to do it, too. Given the maxim "actions speak louder than words," we can expect this first mode of teaching evidence-based practice to be very effective in itself, and it should reinforce what learners derive from other modes.

In the second encounter, the teacher weaves evidence in among the other facts and skills being taught (mode 2 in table 1). When we teach clinical topics with evidence in the mix, we show by example how to integrate evidence with other useful knowledge in the context of preparing to make real clinical decisions, so learners come to see that using evidence is part of good clinical learning. Also, since the evidence and the other knowledge can be learned together, 
Table 13 modes for teaching evidence-based practice on foot

\begin{tabular}{|c|c|c|c|}
\hline & 1. ROLE MODELLING evidence-based practice & $\begin{array}{l}\text { 2. WEAVING evidence in with other } \\
\text { clinical teaching }\end{array}$ & $\begin{array}{l}\text { 3. TARGETING specific skills of } \\
\text { evidence-based practice }\end{array}$ \\
\hline What: & Show the use of evidence in real clinical decisions & $\begin{array}{l}\text { Integrate evidence with other knowledge } \\
\text { when teaching clinical care }\end{array}$ & $\begin{array}{l}\text { Identify specific skills for evidence-based } \\
\text { practice to teach }\end{array}$ \\
\hline Why: & $\begin{array}{l}\text { Learners see the use of evidence as part of good } \\
\text { clinical practice } \\
\text { Teach by example } \\
\text { "Actions speak louder than words" }\end{array}$ & $\begin{array}{l}\text { Learners see the use of evidence as } \\
\text { part of good clinical learning } \\
\text { Teach by explicit guiding on what to } \\
\text { know }\end{array}$ & $\begin{array}{l}\text { Learners develop their abilities to access, } \\
\text { understand, and use evidence } \\
\text { Teach by explicit coaching on skills for } \\
\text { practice }\end{array}$ \\
\hline How: & $\begin{array}{l}\text { "Think aloud" tactic } \\
\text { Show use of evidence resources } \\
\text { Debrief later to reflect on lessons }\end{array}$ & $\begin{array}{l}\text { Select one or few strongest or most } \\
\text { relevant bits of evidence } \\
\text { Show how evidence fits with other } \\
\text { knowledge for action }\end{array}$ & $\begin{array}{l}\text { Select } 1 \text { skill area, and } 1 \text { task within that } \\
\text { area } \\
\text { Coach learners on pragmatic specifics of } \\
\text { that skill in use }\end{array}$ \\
\hline Where: & Practice settings & $\begin{array}{l}\text { Practice settings } \\
\text { Can be done in classroom, too }\end{array}$ & $\begin{array}{l}\text { Practice settings } \\
\text { Can be done in classroom, too }\end{array}$ \\
\hline When: & $\begin{array}{l}\text { Little or no extra time is needed } \\
\text { Can be done almost anytime }\end{array}$ & $\begin{array}{l}\text { May add only } 1-3 \text { minutes to teaching } \\
\text { Can be done almost anytime }\end{array}$ & $\begin{array}{l}\text { May add } 2-5 \text { minutes to teaching } \\
\text { Can be done almost anytime }\end{array}$ \\
\hline Who: & Any teacher, any learner & Any teacher, any learner & Teachers who can coach these skills \\
\hline
\end{tabular}

they might be better organised in memory in the elaborated networks of knowledge so important for clinical thinking. ${ }^{14}$ By using mode 2, we are "putting our money where our mouth is" - that is, spending valuable teaching time and effort on using evidence in context, so we might expect this mode to be effective as well, although we haven't seen either mode 1 or mode 2 studied.

In the third encounter, the teacher targets specific skills within evidence-based practice about which to coach the learners (mode 3 in table 1). By using mode 3, we help our learners develop their abilities for evidence-based learning, which in turn should boost their capacity for lifelong learning and professional development. By targeting 1 or a few specific skills at a time, the teacher makes it possible to fit these learning moments into the schedule of busy practice, knowing that the cumulative learning from many such moments could be great. Here, we get somewhat closer to having evidence about the effectiveness of this approach. The
Cochrane review of trials of teaching critical appraisal skills found some trial evidence of improvements in participants' knowledge. ${ }^{15}$ A recent review of the trials of teaching EBM to postgraduates concluded that standalone teaching improved knowledge, but not skills, attitudes, or behaviour, while teaching that is clinically integrated into routine practice improved knowledge, skills, attitudes, and behaviour. ${ }^{16}$ Although none of the trials appear to have tested the teaching strategies and tactics described above for modes $1-3$, table 1 shows these modes would qualify as "clinically integrated."

Although this essay concerns teaching "on foot," there are other promising ways to teach evidence-based practice that are "clinically integrated" even if they're not "on foot." We'll use the teaching mode structure in table 1 to describe 2 examples. Firstly, in an interactive large group classroom session for students and house officers on the approach to patients with involuntary weight loss, the teacher can include

Table 2 Learning more about teaching evidence-based practice

\begin{tabular}{|c|c|c|}
\hline Strategy or tactic & Why? & How? \\
\hline Deliberate practice of teaching ${ }^{28-29}$ & $\begin{array}{l}\text { Purposeful refinement of teaching craft } \\
\text { "Practice makes perfect" }\end{array}$ & $\begin{array}{l}\text { Select areas on which to focus attention } \\
\text { Identify new or alternate strategy or tactic to try out, eg, } \\
\text { from the "Teaching Tips" series }{ }^{24-27} \\
\text { Practice new strategy or tactic repeatedly, reflecting } \\
\text { after each use on what worked well and what could be } \\
\text { improved }\end{array}$ \\
\hline Keep a teaching journal & $\begin{array}{l}\text { Record observations and interpretations of teaching } \\
\text { and learning experiences } \\
\text { Boosts reflective practice }\end{array}$ & $\begin{array}{l}\text { Take prospective notes on planning, execution, and } \\
\text { reflection of one's teaching } \\
\text { Add observations from others' teaching } \\
\text { Add insights from reading about learning and teaching }\end{array}$ \\
\hline Get coached on teaching & Learn more about teaching from peers and masters & $\begin{array}{l}\text { Identify skilled teachers who are able and willing to be } \\
\text { a teaching coach } \\
\text { Do real teaching while coach observes } \\
\text { Debrief afterward to reflect on the lessons }\end{array}$ \\
\hline $\begin{array}{l}\text { Attend courses on teaching evidence-based } \\
\text { practice }\end{array}$ & $\begin{array}{l}\text { Concentrated focus on building teaching skills and } \\
\text { repertoire during short period of time } \\
\text { Learn through sharing teaching craft with others }\end{array}$ & $\begin{array}{l}\text { Find and attend a course that best fits your learning and } \\
\text { teaching needs }{ }^{34}\end{array}$ \\
\hline Learn more about human learning & $\begin{array}{l}\text { Helps build conceptual models that underlie our } \\
\text { teaching craft } \\
\text { Boosts range of teaching options available } \\
\text { Helps troubleshooting when teaching goes awry }\end{array}$ & $\begin{array}{l}\text { Find and use resources on: } \\
\text { a. human learning in general }{ }^{35-41} \\
\text { b. learning in specific settings, such as in small } \\
\text { groups }{ }^{42-48}\end{array}$ \\
\hline
\end{tabular}


100

evidence about the frequency of underlying diseases in the material covered. In doing so, the teacher has selected to weave the results of research evidence in with other knowledge to guide explicitly the specific decisions and actions, so we can recognise this as teaching in mode 2 in table 1. Secondly, consider a department-wide, daily conference like Morning Report, wherein residents are asked to bring back to the group the evidence-based answers to questions that arose in the care of their patients, using an Educational Prescription. ${ }^{17}$ In addition to facilitating the residents' discussions of their questions, searches, appraisals, and answers, the teacher can also interject relevant and narrowly focused "slices" about the process of evidence-based practice. ${ }^{18}$ Because the teacher is targeting specific skills around which to coach learners, this is teaching in mode 3 in table 1. Most of the clinically integrated forms of teaching we've seen or read about emphasise $\geqslant 1$ of these modes.

Keep in mind that the 3 modes in table 1 are not meant to be either jointly exhaustive (other possible ways exist to teach the wise use of evidence) or mutually exclusive (as hybrids do exist). Furthermore, these modes are complementary, and the best teachers of evidence-based practice use all 3, moving from one to the next to fit the clinical and teaching situation. If we actually use evidence in our own practice and clinical teaching (modes 1 and 2), we'll have more realism and legitimacy when we coach our learners on specific skills of evidence-based practice (mode 3 ).

What can we do to prepare ahead of time to teach in these modes? The following 7 suggestions help us prepare for any mode. Firstly, we should refine our own skills in evidencebased practice, so we're sufficiently competent to serve as role models. Secondly, we can work to gain access to evidence resources we'll need, whether through our healthcare system (local or national) or on our own. Thirdly, because we encounter some problems and decisions repeatedly, we can anticipate the questions we'll have and track down evidencebased answers ahead of time, so they're ready for use. Fourthly, rather than store the entire text of the evidence, we might assemble and keep available concise summaries of the evidence, such as the 1 page summaries from evidence-based synoptic journals such as Evidence-Based Medicine or ACP Journal Club, or from our own CATs (critically appraised topics $)^{19}$ or eCATs. ${ }^{1}$ Fifthly, for some of these recurring decisions, investigative teams have assembled evidencebased decision aids to explicitly guide our patients and ourselves through the processes of integrating evidence with values, so we can retrieve these ahead of time and keep them within reach. ${ }^{20}$ Sixthly, it can be useful to obtain and keep handy some how-to references on evidence-based practice, appropriate to our discipline. ${ }^{13}{ }^{21}$ Seventhly, we should develop our teaching awareness, or reflection-in-action, that allows us to recognise the teaching moments as they occur and helps us choose which to seize and which to let pass. ${ }^{22}$

Beyond these 7 suggestions, a few things can be done ahead of time to prepare to teach in each mode. For mode 1, role modelling, many of us feel more comfortable after practising the use of evidence several times without a watching learner, before being observed by learners using evidence in real patient care. Once we feel comfortable with when, how, and how much evidence to add to our patient encounters, we'll be better able to show others this "flavouring" or "spice" in our practice. For mode 2, we can anticipate that certain bits of evidence will be used alongside predictable aliquots of other knowledge, so we can prepare these mixtures ahead of time, as "teaching vinaigrettes."23 For mode 3, it can help to prepare ahead of time some short (ie, 2-5 min) scripts about the specific skills you'll be targeting, as "teaching slices" of evidence-based practice (not the whole pie), ${ }^{18}$ whether your own or from others. ${ }^{24-27}$

How can we improve further our teaching of evidencebased practice? As a complex craft built on experience as well as knowledge, excellence in teaching takes time to develop. Table 2 includes 5 suggestions for using that time well. Firstly, to develop excellence or even mastery, we probably need to undertake deliberate practice where we purposefully and repeatedly engage in activities designed to improve aspects of our craft. ${ }^{28-29}$ Secondly, we can keep reflective teaching journals to record observations and interpretations of our own teaching, including both successes and failures, ${ }^{30-31}$ as well as observations of other teachers, including those outside clinical medicine. ${ }^{32}$ Thirdly, we can identify respected teachers at our own institutions who can observe our teaching and provide us detailed feedback and coaching. ${ }^{33}$ Fourthly, we can attend one of the growing number of workshops on teaching evidence-based practice being held around the world. ${ }^{34}$ Fifthly, because teaching is so intertwined with learning, we can learn more about how humans learn and how this learning can be facilitated. ${ }^{35-48}$

This essay has focused on how to teach evidence-based practice as part of clinical teaching, not on whether to do so. ${ }^{49} \mathrm{I}$ have tried to collect here the teaching strategies and tactics I and others have found useful, and I look forward to learning more from many of you.

W SCOTT RICHARDSON, MD Wright State University School of Medicine Three Owl Learning Institute Dayton, Ohio, USA

1 Richardson WS, Burdette SD. Taking evidence in hand [editorial]. EvidenceBased Medicine 2003;5:164-5.

2 Badgett RG, Lucey CR, Mulrow CD. Can the clinical examination diagnose leftsided heart failure in adults? JAMA 1997;277:1712-9.

3 Randolph AG, Guyatt GH, Richardson WS. Prognosis in the intensive care unit: finding accurate and useful estimates for counseling patients. Crit Care Med 1998;26:767-72.

4 DeAngelis CD. Professors not professing [editorial]. JAMA 2004;292:1060-1.

5 LaCombe M. High society [commentary]. CMAJ 2002;166:1044-5.

6 Hurst JW. The overlecturing and underteaching of clinical medicine. Arch Intern Med 2004;164:1605-8.

7 Morgan WL Jr. Bedside teaching. Trans Am Clin Climatol Assoc 1981;93:164-71.

8 Fitzgerald FT. Bedside teaching. West J Med 1993;158:418-20.

9 Kroenke K, Omori DM, Landry FJ, et al. Bedside teaching. South Med J 1997;90:1069-74.

10 LaCombe MA. On bedside teaching. Ann Intern Med 1997;126:217-20.

11 Sackett DL, Rosenberg WMC, Gray JAM, et al. Evidence based medicine: what it is and what it isn't [editorial]. BMJ 1996;312:71-2.

12 Richardson WS. One, two, three ... teach! Evidence-Based Health Care Newsletter 1999;19:6-7.

13 Straus SE, Richardson WS, Glasziou P, et al, editors. Evidence-based medicine: how to practice and teach EBM. 3rd ed. Edinburgh, UK: Churchill Livingstone, 2005.

14 Bordage G. Elaborated knowledge: a key to successful diagnostic thinking. Acad Med 1994;69:883-5.

15 Parkes J, Hyde C, Deeks J, et al. Teaching critical appraisal skills in health care settings. Cochrane Database Syst Rev 2002;(4):CD001270.

16 Coomarasamy A, Khan KS. What is the evidence that postgraduate teaching in evidence based medicine changes anything? BMJ 2004;329:1017-21

17 Richardson WS. Teaching evidence-based medicine in morning report. Clinical Epidemiology Newsletter 1993;13:9.

18 Richardson WS. One slice or the whole pie? Evidence-Based Health Care Newsletter 2001;21:17-8.

19 Sauve S, Lee HN, Meade MO, et al. The critically appraised topic: a practical approach to learning critical appraisal. Ann R Coll Physicians Surg Can 1995;28:396-8.

$20 \mathrm{O}^{\prime}$ Connor AM, Legare F, Stacey D. Risk communication in practice: the contribution of decision aids. BMJ 2003;327:736-40.

21 Guyatt GH, Rennie DR, editors. Users' guides to the medical literature: a manual for evidence-based practice. Chicago, IL: AMA Press, 2002.

22 Branch WT Jr, Paranjape A. Feedback and reflection: teaching methods for clinical settings. Acad Med 2002;77:1 185-8.

23 Richardson WS. Teaching vinaigrettes. Evidence-Based Health Care Newsletter 2004;24:11. 
24 Wyer PC, Keitz S, Hatala RM, et al. Tips for learning and teaching evidence based medicine: introduction to the series [commentary]. CMAJ 2004; 171:347-8

25 Barratt A, Wyer PC, Hatala R, et al, for the Evidence-Based Medicine Teaching Tips Working Group. Tips for learners of evidence-based medicine: 1. Relative risk reduction, absolute risk reduction and number needed to treat. CMAJ 2004; 171:353-8.

26 Montori VM, Kleinbart J, Newman TB, et al, for the Evidence-Based Medicine Teaching Tips Working Group. Tips for learners of evidence-based medicine: 2. Measures of precision (confidence intervals). CMAJ 2004;171:611-5.

27 McGinn TG, Wyer PC, Newman TB, et al, for the Evidence-Based Medicine Teaching Tips Working Group. Tips for learners of evidence-based medicine: 3. Measures of observer variability (kappa statistic). CMAJ 2004;171:1369-73.

28 Ericsson KA. Deliberate practice and the acquisition and maintenance of expert performance in medicine and related disciplines. Acad Med 2004;79(10 Suppl I):S70-81.

29 Ericsson KA, editor. The road to excellence: the acquisition of expert performance in the arts and sciences, sports, and games. Mahwah, NJ: Lawrence Erlbaum, 1996.

30 Pinsky LE, Monson D, Irby DM. How excellent teachers are made: Reflecting on success to improve teaching. Adv Health Sci Educ Theory Pract 1998;3:207-15.

31 Pinsky LE, Irby DM. "If at first you don't succeed": using failure to improve teaching. Acad Med 1997;72:973-6.

32 Conn JJ. What can clinical teachers learn from Harry Potter and the Philosopher's Stone? Med Educ 2002;36:1176-81

33 Beckman TJ. Lessons learned from a peer review of bedside teaching. Acad Med 2004:79:343-6.
34 Richardson WS. A teacher's dozen. Nordic Evidence-Based Health Care Newsletter 2001;5:16-7.

35 Schon DA. Educating the reflective practitioner: toward a new design for teaching. San Francisco, CA: Jossey-Bass, 1987.

36 Candy PC. Self-direction for lifelong learning: a comprehensive guide to theory and practice. San Francisco, CA: Jossey-Bass, 1991.

37 Neighbour R. The inner apprentice: an awareness-centred approach to vocational training for general practice. Newbury, UK: Petroc Press, 1996.

38 Palmer PJ. The courage to teach: exploring the inner landscape of a teacher's life. San Francisco, CA: Jossey-Bass, 1998.

39 Claxton G. Wise-up: the challenge of lifelong learning. New York, NY: Bloomsbury, 1999.

40 Bransford JD, Brown AL, Cocking RR, editors. How people learn: brain, mind, experience, and school. Washington, DC: National Academy Press, 2000.

41 Brown JS, Duguid P. The social life of information. Boston, MA: Harvard Business School Press, 2000.

42 Tiberius RG. Small group teaching: a troubleshooting guide. Toronto, Ontario: OISE Press, 1990

43 Westberg J, Jason H. Fostering learning in small groups: a practical guide. Philadelphia, PA: Springer, 1996.

44 Brookfield SD, Preskill S. Discussion as a way of teaching: tools and techniques for democratic classrooms. San Francisco, CA: Jossey-Bass, 1999

45 Maudsley $\mathrm{G}$. Roles and responsibilities of the problem based learning tutor in the undergraduate medical curriculum. BMJ 1999;318:657-61.

46 Jaques D. Learning in groups, $3^{\text {rd }}$ ed. London, UK: Kogan Page, 2000

47 Wood DF. Problem based learning. BMJ 2003;326:328-30.

48 Jaques D. Teaching small groups. BMJ 2003;326:492-4.

49 Whitcomb ME. Why we must teach evidence-based medicine [editorial]. Acad Med 2005;80:1-2.

\section{Finding the gold in Medline: clinical queries}

$M$ edline is the premier source for access to the broad spectrum of the medical literature. With $>15000000$ references from $>4800$ biomedical journals, the Medline treasure trove contains citations for virtually all the gold that the biomedical research enterprise has to offer.

But finding exactly what you want in such a huge database has its challenges. Firstly, the indexing is fairly coarsely grained, so that it can be difficult to specify exactly what you are seeking. Secondly, the English language is notorious for synonyms, homonyms, eponyms, and neologisms, making it impossible to include all the possible variants, while at the same time ensuring that you will retrieve many unwanted citations. Thirdly, few doctors have adequate training and competency for searching Medline. Fourthly, even if you find something that appears to be what you want, it is impossible to be sure that you have not missed something that is even better. Finally and worst of all, the concentration of articles that exactly match what you need is so dilute that even the finest search sieve will scoop up mostly silt.

To reduce these problems, over a decade ago we developed and tested search filters for Medline that would sort the gold from the silt. To do this, we used the approach of validating diagnostic tests, using proposed search terms as "tests" and a hand search of 10 clinical journals as the "gold standard." For the hand search, we used a limited version of the criteria that are currently used for selecting articles for ACP Journal Club (www.acpjc.org/shared/purpose_and_procedure.htm), Evidence-Based Medicine, and Evidence-Based Nursing. For example, for therapy, an article "passed" the methodological screen during the hand search if there was random allocation of participants to comparison groups. This was the only criterion required for therapy articles. The most specific and sensitive of several hundred single terms and many thousands of combined terms were identified this way. We did this for 4 topic areas: diagnosis, prognosis, treatment, and etiology. The US National Library of Medicine (NLM), which funded this research, then put the best strategies into a special PubMed web page, Clinical Queries (www.ncbi.nlm. nih.gov/entrez/query/static/clinical.html), so that anyone interested in these topics could conduct searches at a level that is likely beyond what even an experienced librarian could achieve.

Recently, we completed a new study that tackles developing strategies in a much larger database, 170 journals (161

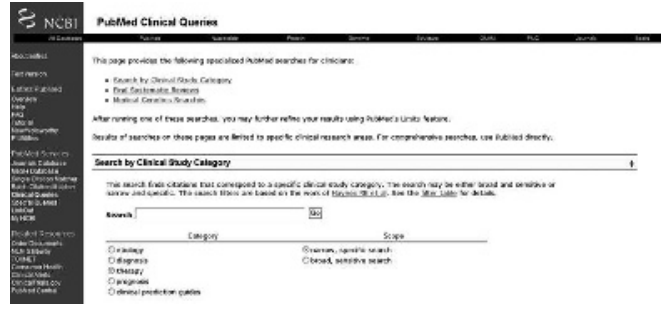

Figure 1.

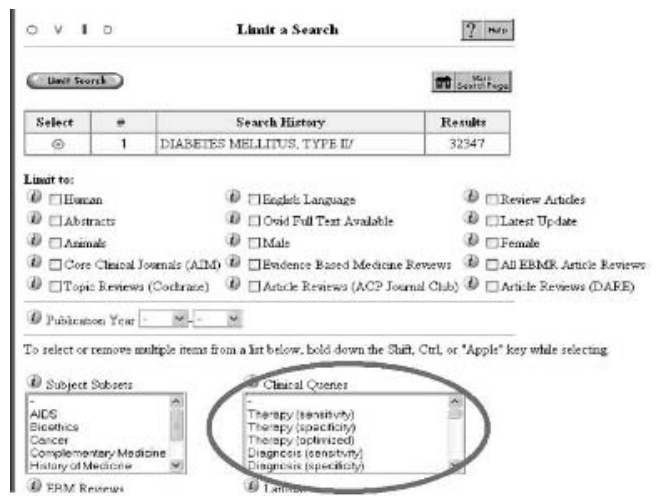

Figure 2. 


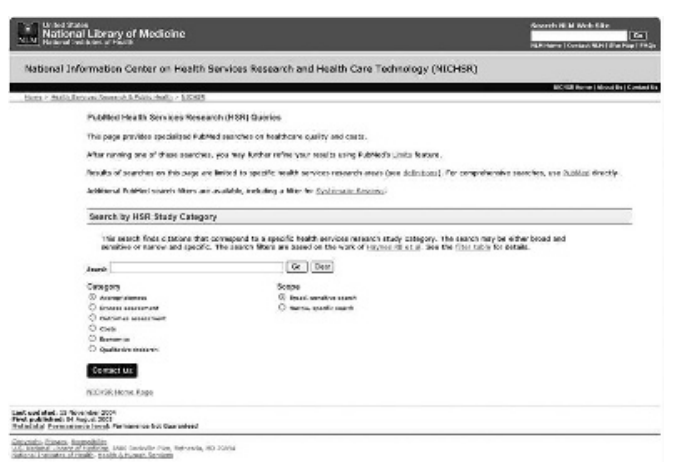

Figure 3.

journals of which are indexed by Medline), using the same criteria for selecting articles as used in ACP Journal Club, Evidence-Based Medicine, and Evidence-Based Nursing, and testing $>5000$ single terms and many thousands of combined terms. These search strategies work better than their predecessors and have now replaced them in Clinical Queries (figure 1).

The most sensitive strategies retrieve well over $90 \%$ of the relevant studies in Medline, and for therapy, for example, $>99 \%$ of studies are retrieved. In addition, they have been incorporated into the Ovid search engine (as "limits" that can be invoked once you have entered one or more content terms) (figure 2). Ovid supplies access to Medline for many institutional libraries. The Ovid version of the search strategies has many additional features. Clinical Queries covers just the 4 topics mentioned above and clinical prediction guides, and provides only the most sensitive and the most specific search strategies for them. Ovid provides all these, but also includes searches that we developed for 4 other topics areas: qualitative studies, review articles, and studies of costs and economics. Furthermore, Ovid provides search strategies that best balance sensitivity and specificity (optimized strategies). Finally, these optimised search strategies have also been incorporated into SKOLAR (www. skolar.com), a clinical database available through Ovid.

In addition to the clinical search strategies, we have developed search strategies for health services research topics addressing the appropriateness, process, and outcomes of care, and clinical practice guidelines. These are on another NLM website (www.nlm.nih.gov/nichsr/hedges/search.html) (figure 3), available for searching Medline through PubMed using these strategies. PubMed's homepage also provides a link to health services research strategies (click on Special Queries, just below the Clinical Queries link).

Altogether, these search strategies can greatly enhance your ability to retrieve original studies and reviews indexed in Medline that are important to clinical practice and the delivery of health care. We hope you will make use of them when you cannot find what you need from existing evidencebased resources.

\section{Measures of association as used to address therapy, harm, and aetiology questions}

\section{WHAT ARE MEASURES OF ASSOCIATION?}

Measures of association describe the strength of the relationship between an exposure (or intervention) and an outcome in clinical studies (randomised controlled trials [RCTs], cohort studies, and case control studies). There are 2 types of measures: relative (relative risk, relative risk reduction, odds ratios) and absolute (absolute risk reduction, number needed to treat).

Confidence intervals (CI) should be given for each measure of association to quantify their uncertainty and are usually reported as $95 \%$ CI (ie, the interval has a $95 \%$ chance of including the true, but unknown, population value). If the $95 \%$ CI overlaps the value of no effect (see below), the result is not statistically significant at the $5 \%$ level $(p<0.05)$. The use of $\mathrm{p}$ values and CIs to measure statistical uncertainty will be considered in a future statistics note.

The identification of a statistically significant association between an exposure and an outcome alone does not imply causation. Possible bias and consistency need to be considered. ${ }^{1-3}$ When addressing therapy, harm, or aetiology questions, a systematic review of $\geqslant 2$ double blind RCTs typically provides more convincing evidence than an individual RCT, which again provides more convincing evidence than an individual cohort or case control study.

\section{WHEN ARE THEY USED?}

All of the absolute and relative measures of association described above can be used in RCTs and cohort studies. In case control studies, however, only odds ratios should be calculated because in such a study the prevalence of the outcome (eg, a disease) is not known as the groups are determined by outcome rather than exposure status.

\section{HOW ARE THEY CALCULATED?}

The most common measures are calculated below using the results from probably the earliest RCT, which evaluated the role of streptomycin in the treatment of tuberculosis (TB): ${ }^{4}$

\begin{tabular}{|c|c|c|c|c|c|}
\hline \multirow[t]{2}{*}{ Patients } & \multirow[t]{2}{*}{ Randomisation } & \multirow[t]{2}{*}{ Intervention } & \multirow[t]{2}{*}{ Follow up } & \multicolumn{2}{|c|}{ Outcome at 6 months } \\
\hline & & & & Alive & Dead \\
\hline $\begin{array}{l}\mathrm{N}=107,15-30 \text { year } \\
\text { old men and women }\end{array}$ & & $\begin{array}{l}\text { Streptomycin and } \\
\text { bedrest }(n=55)\end{array}$ & & 51 & 4 \\
\hline $\begin{array}{l}\text { with acute bilateral } \\
\text { pulmonary TB }\end{array}$ & & $\begin{array}{l}\text { Placebo and } \\
\text { bedrest }(n=52)\end{array}$ & 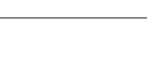 & 38 & 14 \\
\hline
\end{tabular}


Q: What proportion died on streptomycin?

- 4 out of 55 or $7.3 \%$.

- This percentage is called the experimental event risk (EER).

\section{Q: What proportion died on placebo?}

- 14 out of 52 or $26.9 \%$.

- This percentage is called the control event risk (CER).

- Some authors call the EER and CER "rates" instead of risks, which is technically inaccurate as rates describe the number of events per person time.

\section{ABSOLUTE RISK REDUCTION (ARR)}

\section{Q: What was the difference in risk of death between} the two groups?

- $\mathbf{1 9 . 6 \%}$ (95\% CI $\mathbf{5 . 7 \%}$ to $\mathbf{3 3 . 6 \% )}$ more people died on placebo compared with streptomycin. This result is statistically significant at the 5\% level because the 95\% CI does not overlap the value of no effect $(A R R=0 \%)$.

- This is called the absolute risk reduction (ARR) and is calculated by subtracting the EER from the CER.

$$
\mathrm{ARR}=\mathrm{CER}-\mathrm{EER}=26.9 \%-7.3 \%=19.6
$$

- When positive outcomes are considered (eg, survival), and the intervention is more helpful than the control, this is called the absolute benefit increase (ABI).

\section{NUMBER NEEDED TO TREAT (NNT)}

Q: How many people with TB would I need to treat with streptomycin to prevent 1 additional death

- 6 (95\% CI 3 to 18$)$ patients with TB would need to be treated with streptomycin to prevent 1 additional person dying. This result is statistically significant at the $5 \%$ level because the $95 \%$ CI does not overlap the value of no effect $(\mathrm{NNT}=$ infinity when ARR $=0 \%)$. The word "additional" is used to stress the fact that not everybody died on placebo.

- This measure is called the number needed to treat (NNT). The NNT is usually rounded up to the nearest whole number to provide a more conservative estimate of the added value of the intervention.

- The NNT is the reciprocal of the ARR.

$$
\mathrm{NNT}=\frac{1}{\mathrm{ARR}}=\frac{1}{19.6 \%}=\frac{1}{(19.6 / 100)}=5.1=6
$$

- A negative NNT is also known as the number needed to harm (NNH).

$$
\begin{array}{r}
\text { STUART CARNEY, MB, ChB, } \\
\text { MPH, MRCPsych } \\
\text { Department of Psychiatry, University of Oxford } \\
\text { Oxford, UK }
\end{array}
$$

HELEN DOLL, BSc, DIP APP STATS, MSC Department of Public Health, University of Oxford Oxford, UK

\section{RELATIVE RISK (RR)}

Q: What was the risk of dying on streptomycin relative to placebo?

- The bar graph shows that for every 1 patient who died on streptomycin, approximately 4 patients died on placebo (27/7).

- This is called the relative risk (RR). The RR compares the risk of death in the intervention group (EER) with the risk of death in the control group (CER).

$$
\mathrm{RR}=\frac{\mathrm{EER}}{\mathrm{CER}}=\frac{7.3 \%}{26.9 \%}=0.27
$$

- The relative risk of dying on streptomycin compared with placebo was 0.27 (95\% CI 0.10 to 0.77$)$. This result is statistically significant at the $5 \%$ level because the $95 \%$ CI does not overlap the value of no effect $(\mathrm{RR}=1)$.

\section{RELATIVE RISK REDUCTION (RRR)}

$Q$ : How much less common was death on streptomycin compared with placebo?

- Treatment with streptomycin was associated with a $\mathbf{7 3 \%}$ (95\% CI $23 \%$ to $90 \%$ ) reduction in the risk of death compared with placebo. In other words, antibiotic treatment prevented approximately three quarters of the deaths that would have occurred on placebo. This result is statistically significant at the 5\% level because the $95 \%$ CI does not overlap the value of no effect $(\mathrm{RRR}=0 \%)$.

- This is called the relative risk reduction (RRR) and is commonly used in promotional literature distributed by pharmaceutical companies.

- The RRR can be calculated by either dividing the ARR by the CER or subtracting the RR from 1.

$$
\mathrm{RRR}=\mathrm{I}-\mathrm{RR}=\frac{\mathrm{ARR}}{\mathrm{CER}}=\frac{19.6 \%}{26.9 \%}=0.73=73 \%
$$

- When positive outcomes are considered and the intervention is more helpful than the control, this is called the relative benefit increase $(\mathrm{RBI})$.

1 Hill AB. Proc Roy Soc Med 1965;58:295-300.

2 Rothman KJ. Am J Epidemiol 1976;104:587-592

3 Susser M. Am J Epidemiol 1991;133:635-48.

4 Medical Research Council. BMJ 1948;ii:769-782. 